\title{
Hernia after retroperitoneoscopic adrenalectomy, case report
}

\author{
Christian T. J. Magyar, Christian A. Nebiker \\ ${ }^{1}$ Resident in Surgery, ${ }^{2}$ Consultant Surgeon, Klinik für Viszeralchirurgie, Kantonsspital Aarau, Aarau, Switzerland \\ Correspondence to: Christian A. Nebiker, PD, Dr. Med. Consultant Surgeon, Klinik für Viszeralchirurgie, Kantonsspital Aarau, Tellstrasse 25, 5001 \\ Aarau, Switzerland. Email: christian.nebiker@ksa.ch.
}

\begin{abstract}
We report the first case of a previously undocumented complication after posterior retroperitoneal adrenalectomy (PRA). Extensive diagnostic procedures for persisting abdominal pain led to diagnosis of an incisional hernia (IH) approximately 2.5 years after surgery for a pheochromocytoma of the right adrenal gland. Thus, IHs need to be recognized as a potential complication after PRA, particularly if the symptoms are non-specific. The differential diagnosis of an IH after PRA includes a type of spontaneous lumbar hernia due to a pre-existing weakness of the abdominal wall however the treatment for both type of hernias is similar by mesh repair. A possible risk factor for IH after PRA might be obesity, due to different factors including difficulties in closing the fascia in depth under subcutaneous tissue.
\end{abstract}

Keywords: Adrenalectomy; complications; hernia; retroperitoneoscopy; case report

Submitted Nov 14, 2019. Accepted for publication Jan 08, 2020.

doi: 10.21037 /gs.2020.01.03

View this article at: http://dx.doi.org/10.21037/gs.2020.01.03

\section{Introduction}

It is essential to be aware of and to discuss surgical complications and their treatment options, especially as 'new' surgical techniques develop. In 1992, Gagner published the first outcomes of laparoscopic adrenalectomy compared with the previously used open technique, and this rapidly became the gold standard (1). Subsequently, several laparoscopic approaches have evolved including the anterior transperitoneal adrenalectomy (ATA), lateral transperitoneal adrenalectomy (LTA), lateral retroperitoneal adrenalectomy as well as posterior retroperitoneal adrenalectomy (PRA) (2-6). Moreover, the concept of minimally-invasive surgery offers the options of single-access (also called as single incision laparoscopic surgery) or access using multiple-ports or incisions (7).

To our knowledge, incisional hernia (IH) has not previously been evaluated nor discussed in detail as a possible complication after PRA (8). Given the lack of information in the literature, as well as the fact that PRA only involves surgery within the retroperitoneal space without involving intraabdominal incisions or structures, we present a case report of IH after PRA, a rapidly evolving field of endocrine surgery. We present the following case in accordance with the CARE Guideline (9).

\section{Case presentation}

A 44-year-old female patient of Italian origin presented to the emergency department with a 3-week history of colicky abdominal pain mainly in the upper right quadrant, along with abdominal distension and episodes of palpations, pallor and intensive sweating. Computer tomography (CT) and a (nor)metanephrine blood analysis were performed and a pheochromocytoma of the right adrenal gland, $5 \mathrm{~cm}$ in maximum diameter, was diagnosed (Figure 1A). Concomitant diagnoses included secondary hyperaldosteronism, chronic autoimmune thyroiditis and obesity $[165 \mathrm{~cm}, 131 \mathrm{~kg}$, body mass index (BMI): $48.1 \mathrm{~kg} / \mathrm{m}^{2}$ ].

PRA with complete resection of the right adrenal gland was performed 35 days after the CT scan. The surgical technique used in our clinic is similar to the conventional three-port PRA proposed by Walz et al. (10). With the patient in the prone position, incisions for the trocars were made below the tip of the $12^{\text {th }}$ right rib (12 $\mathrm{mm}$ trocar), lateral beneath $11^{\text {th }}$ rib (12 mm trocar) and paravertebral to the vertebrocostal joints below the $12^{\text {th }}$ rib $(5 \mathrm{~mm}$ trocar). The thoracolumbar fascia, the transversalis fascia and the 

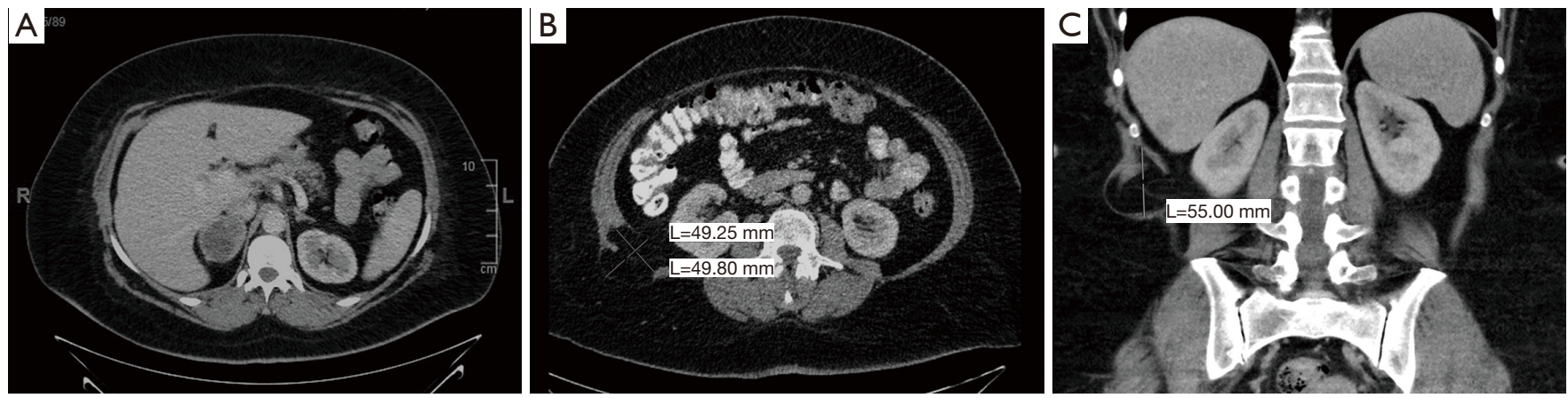

Figure 1 CT imaging of patient, demonstrating the (A) pheochromocytoma and (B,C) hernia. (A,B) Transverse CT abdomen; (C) coronal CT abdomen. CT, computer tomography.

posterior lamina of the renal fascia (originally described by and named after Zuckerkandl) were incised to gain access to the perirenal space (11) where the capno-retroperitoneum was created with a pressure of approximately $20 \mathrm{mmHg}$. The perirenal space is limited anteriorly through the adjacent anterior lamina of the renal fascia [commonly called Gerota fascia (12)], which was not incised during the procedure. Retracting the kidney, the adrenal gland was mobilized and completely resected. Usually, the thoracolumbar fascia is closed using Vicryl ${ }^{\circledR}$ in a single stitch technique. However, in this case the surgeon abstained from suturing the fascia, due to a $10 \mathrm{~cm}$ layer of subcutaneous fat tissue. The wound was closed by suturing in layers and the patient was discharged home on the $5^{\text {th }}$ postoperative day.

Clinical follow-up was performed on day 42 after surgery. The patient had no complaints and wound healing was unremarkable. Approximately 1 year later, the patient again presented to the emergency department with colicky abdominal right upper quadrant pain. A series of investigations including ultrasound, colonoscopy and gastroscopy failed to detect the underlying cause.

Due to persisting pain in the upper right quadrant and back pain whilst coughing, the patient again presented to our outpatient department. On examination, a possible hernia was detected on coughing below the $12^{\text {th }}$ right rib. A contrast-enhanced CT, performed 2.5 years after surgery, revealed a hernia in the right lumbar region which measured $49 \times 49 \times 55 \mathrm{~mm}$ and the outer pole of which was located under approximately $60 \mathrm{~mm}$ of subcutaneous fatty tissue (Figure 1B,C). On ultrasound, a difference in size of the hernia in the prone and upright positions was noted $(23 \times 16$ vs. $48 \times 25 \mathrm{~mm})$. In both CT and ultrasound, the hernial sac was seen to be filled with adipose tissue.

Reconstructive surgery of the lumbar hernia was performed 2.7 years after the initial PRA. Incision through the PRA scar was performed in a prone position (the Heidelberg position). After careful preparation, a hernial sac of $60 \times 40 \mathrm{~mm}$ (Figure $2 A$ ) was incised and resected (Figure $2 B$ ). The $12^{\text {th }}$ subcostal nerve was identified and carefully spared. The fascia was closed with a mesh in a sublay position. A VIPRO- $2^{\circledR} 8 \times 7 \mathrm{~cm}$ mesh was adjusted and fitted to an ovaloid shape and sutured using Vicryl ${ }^{\circledR}$ 2-0 (Figure 2C). Above the fascia, the external and internal oblique abdominal muscles were sutured using Vicryl ${ }^{\circledR}$ 2-0 (Figure 2D). After inserting a subcutaneous drain, the wound was closed in layers. The patient was discharged home on the second postoperative day.

At follow-up 50 days after the hernia repair, the patient had no lumbar pain, clinically unremarkable scars and no palpable bulge on the Valsalva maneuver. The timeline for the patient is outlined in Figure 3.

\section{Discussion}

To our knowledge, this is the first publication reporting and discussing herniation as a complication after PRA. A randomized clinical trial with a 5-year follow-up of 30 patients after PRA for unilateral adrenalectomy did not report any hernias (8) whereas a retrospective study of 560 PRA procedures mentions one case of hernia (10). On the other hand, IH after ATA or LTA have been discussed $(13,14)$ as well as after other types of retroperitoneal surgery (e.g., nephrectomy) (15-18). We report an IH, a rare complication of PRA requiring surgical intervention and highlight four different aspects from our own experience.

Firstly, due to the rarity of the IH after PRA, the diagnosis and treatment of the $\mathrm{IH}$ in our patient was delayed with adverse effects on her quality of life. The time 

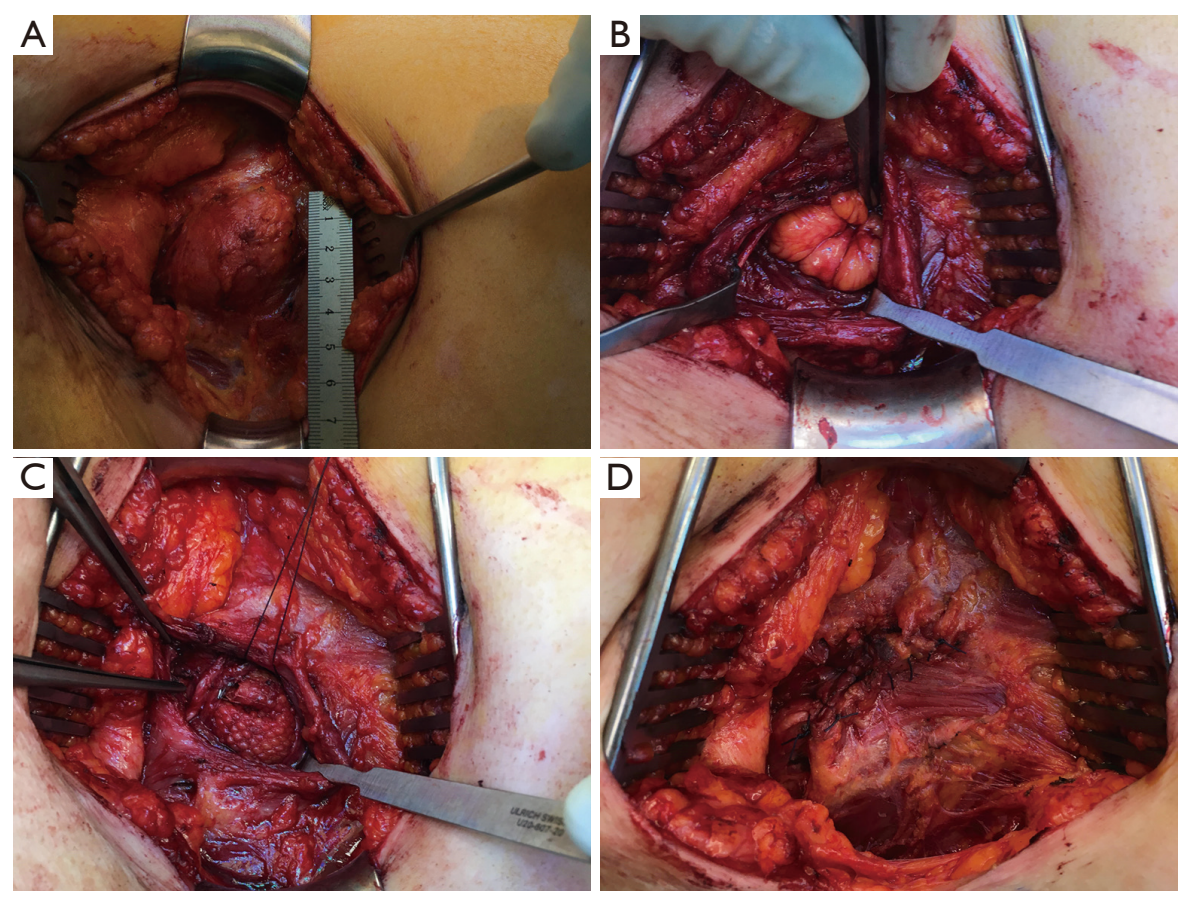

Figure 2 Intraoperative photographs demonstrating the main steps of the hernia repair. (orientation clockwise with 12 o'clock: medial, 3 o'clock: cranial, 6 o'clock: lateral, 9 o'clock: caudal). (A) Preparation of the hernial sac; (B) resection of the hernial sac; (C) VIPRO-2 mesh implantation in a sublay position; (D) suture of adjacent muscle layers.

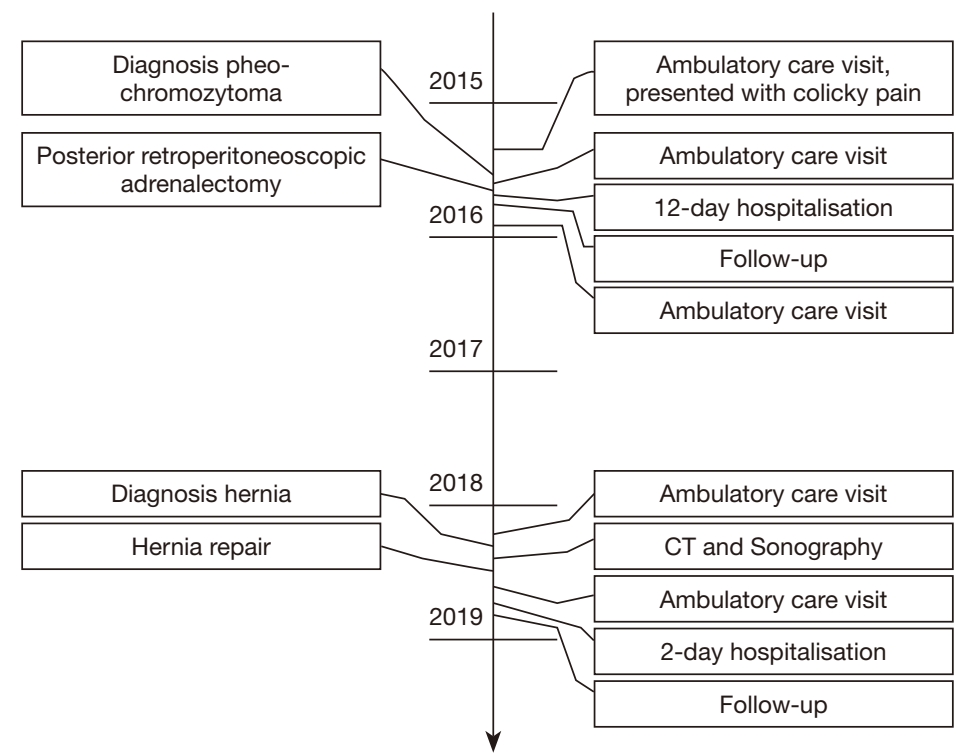

Figure 3 Timeline of visits, interventions and diagnosis for a patient with initially diagnosed pheochromocytoma treated with posterior retroperitoneoscopic adrenalectomy and delayed diagnosis of hernia. 
to diagnosis was 2.5 years and time to treatment 2.7 years. In the case series mentioned above, surgical repair was also performed approximately 2 years after the initial PRA (10). Therefore, we consider it essential to evaluate symptoms which might be compatible with IH after PRA.

Secondly, not all hernias in the lumbar region are IHs. A differential diagnosis is a spontaneous lumbar hernia such as the Grynfelt-Lesshaft (GLH) or Petit hernia. GLH accounts for approximately $2 \%$ of abdominal hernias located below the $12^{\text {th }}$ thoracic rib, the internal abdominal oblique muscle and the erector spinae muscle group (19). And thus, it seems that this part of the abdominal wall is predisposed to herniation. Due to the location of the hernia in our case, whether it was an IH or a spontaneous lumbar hernia is open to discussion. However, differentiation between the two types of hernia is unfeasible retrospectively as the trocars were placed in close proximity to the site where GLHs arise. A possible surgical procedure to repair a GLH was suggested by Ploneda-Valencia et al. using an onlay mesh repair (19), whereas we used a sublay mesh repair. Both approaches seem feasible for hernias in this specific region of the abdominal wall.

Thirdly, PRA is a surgical intervention where surgical maneuvers are performed only in the retroperitoneal space and, if performed correctly, no damage to the peritoneum occurs. Furthermore, the retroperitoneal fat tissue und the kidney contribute to a natural reinforcement of the abdominal wall, and subsequent herniation should occur less frequently than after transabdominal interventions. On the other hand, during PRA, the transverse abdominal fascia, thoracolumbar fascia, as well as posterior lamina of the renal fascia are transected. The latter has been reported to be one of the thickest visceral fasciae in the human body with thickness in autopsy studies of $1,009( \pm 105)$ micrometer $(20)$. We consider an understanding of the anatomy of the fasciae, the retroperitoneal space as well as anatomically weak areas of the abdominal wall to be crucial when performing PRA. A change of suture technique, whilst always trying to close the fascia, or material might be considered in order to decrease the likelihood of herniation.

Fourth, possible risk factors for IH after PRA need to be identified and further studies are warranted. Obesity might be a risk factor for multiple reasons. Suturing of the fasciae in deep fat layers might be insufficient due to poor visibility and difficult manipulation. Additionally, obesity can lead to increased intraabdominal pressure and consequently an increased strain on the abdominal wall.

In conclusion, the complication of herniation after PRA should be included in the differential diagnosis of patients with persistent postoperative abdominal symptoms.

\section{Acknowledgments}

Thanks go to Susanne Rogers for proofreading and editing the manuscript.

Funding: None.

\section{Footnote}

Conflicts of Interest: Both authors have completed the ICMJE uniform disclosure form (available at http://dx.doi. org/10.21037/gs.2020.01.03). The authors have no conflicts of interest to declare.

Ethical Statement: The authors are accountable for all aspects of the work in ensuring that questions related to the accuracy or integrity of any part of the work are appropriately investigated and resolved. Written informed consent was obtained from the patient for publication of this Case report and accompanying images.

Open Access Statement: This is an Open Access article distributed in accordance with the Creative Commons Attribution-NonCommercial-NoDerivs 4.0 International License (CC BY-NC-ND 4.0), which permits the noncommercial replication and distribution of the article with the strict proviso that no changes or edits are made and the original work is properly cited (including links to both the formal publication through the relevant DOI and the license). See: https://creativecommons.org/licenses/by-nc-nd/4.0/.

\section{References}

1. Gagner M, Lacroix A, Bolté E. Laparoscopic adrenalectomy in Cushing's syndrome and pheochromocytoma. N Engl J Med 1992;327:1033.

2. Alesina PF. Retroperitoneal adrenalectomy-learning curve, practical tips and tricks, what limits its wider uptake. Gland Surg 2019;8:S36-40.

3. Gaujoux S, Mihai R, joint working group of ESES and ENSAT. European Society of Endocrine Surgeons (ESES) and European Network for the Study of Adrenal Tumours (ENSAT) recommendations for the surgical management of adrenocortical carcinoma. Br J Surg 2017;104:358-76.

4. Brunt LM. SAGES Guidelines for minimally invasive treatment of adrenal pathology. Surg Endosc 
2013;27:3957-9.

5. Walz MK. Minimal-invasive Nebennierenchirurgie. Der Chirurg 2012;6:536-45.

6. Puccini M, Panicucci E, Candalise V, et al. The role of laparoscopic resection of metastases to adrenal glands. Gland Surg 2017;6:350-4.

7. Walz MK, Groeben H, Alesina PF. Single-access retroperitoneoscopic adrenalectomy (SARA) versus conventional retroperitoneoscopic adrenalectomy (CORA): a case-control study. World J Surg 2010;34:1386-90.

8. Barczyński M, Konturek A, Nowak W. Randomized clinical trial of posterior retroperitoneoscopic adrenalectomy versus lateral transperitoneal laparoscopic adrenalectomy with a 5-year follow-up. Ann Surg 2014;260:740-7; discussion 747-8.

9. Riley DS, Barber MS, Kienle GS, et al. CARE guidelines for case reports: explanation and elaboration document. J Clin Epidemiol 2017;89:218-35.

10. Walz MK, Alesina PF, Wenger FA, et al. Posterior retroperitoneoscopic adrenalectomy--results of 560 procedures in 520 patients. Surgery 2006;140:943-8; discussion 948-50.

11. Palmer DA, Moinzadeh A. Surgical, radiographic, and endoscopic anatomy of the retroperitoneum. In: Wein AJ, Kavoussi LR, Partin AW, et al. editors. Campbell-Walsh urology, 11th edition. Philadelphia: Elsevier, 2016:765-83.

12. Kanemura T, Satake K, Nakashima H, et al. Understanding retroperitoneal anatomy for lateral approach spine surgery. Spine Surg Relat Res 2017;1:107-20.

Cite this article as: Magyar CTJ, Nebiker CA. Hernia after retroperitoneoscopic adrenalectomy, case report. Gland Surg 2020;9(2):442-446. doi: 10.21037/gs.2020.01.03
13. Hubertus J, Pohl A, Schmid I, et al. Laparoscopic adrenalectomy is feasible for suspected adrenal tumors in children younger than 24 months of age - but is it always justified? Klin Padiatr 2016;228:135-8.

14. Dokumcu Z, Divarci E, Ertan Y, et al. Laparoscopic adrenalectomy in children: a 25-case series and review of the literature. J Pediatr Surg 2018;53:1800-5.

15. Koch M, Kroencke S, Li J, et al. Structured introduction of retroperitoneoscopic donor nephrectomy provides a high level of safety and reduces the physical burden for the donor compared to an anterior mini incision: a cohort study. Int J Surg 2019;69:139-45.

16. Kumar M, Kumar R, Hemal AK, et al. Complications of retroperitoneoscopic surgery at one centre. BJU Int 2001;87:607-12.

17. Hemal AK, Gupta NP, Wadhwa SN, et al.

Retroperitoneoscopic nephrectomy and nephroureterectomy for benign nonfunctioning kidneys: a single-center experience. Urology 2001;57:644-9.

18. Barlas IS, Aydogdu I, Sinangil A, et al. Hand-assisted nephrectomy predisposes incisional herniation in obese living donors. Transplant Proc 2019;51:2210-4.

19. Ploneda-Valencia CF, Cordero-Estrada E, CastañedaGonzález LG, et al. Grynfelt-Lesshaft hernia a case report and review of the literature. Ann Med Surg (Lond) 2016;7:104-6.

20. Stecco C, Sfriso MM, Porzionato A, et al. Microscopic anatomy of the visceral fasciae. J Anat 2017;231:121-8. 